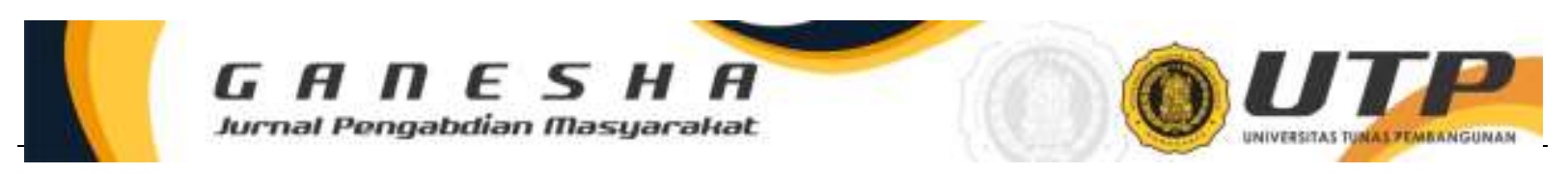

\title{
PENDAMPINGAN PERENCANAAN DAN PERANCANGAN KAMPUNG WISATA NGEPUNGSARI KECAMATAN JATIPURO KABUPATEN KARANGANYAR
}

\author{
Rully ${ }^{1}$, Wahyu Prabowo ${ }^{2}$ \\ ${ }^{1,2}$ Universitas Tunas Pembangunan Surakarta \\ Email Korespondensi: rully@lecture.utp.ac.id
}

\begin{abstract}
Abstrak
Perencanaan dan perancangan Kampung Wisata Ngepungsari, Kecamatan Jatipuro Kabupaten Karanganyar ini dilaksanakan untuk membantu masyarakat di lingkungan Desa Ngepungsari kecamatan Jatipuro kabupaten Karanganyar dalam hal peningkatan pendapatan ekonomi serta pengembangan pariwisata . Pembangunan ini dilakukan secara swadaya. Kesulitan yang dihadapi oleh masyarakat dalam perencanaan dan perancangan Kampung wisata ini adalah bagaimana membuat desain kampung wisata yang baik secara arsitektural, diharapkan kampung wisata ini akan menjadi kebanggaan warganya dan dapat menumbuhkembangkan kegiatan kepariwisataan dan peningkatan pendapatan ekonomi seluruh warganya.
\end{abstract}

Kata kunci: perencanaan, perancangan, kampung, wisata, arsitektural

\begin{abstract}
The planning and design of the Ngepungsari Tourism Village, Jatipuro District, Karanganyar Regency was carried out to help the community in the Ngepungsari Village, Jatipuro District, Karanganyar Regency in terms of increasing economic income and tourism development. This development is done independently. The difficulty faced by the community in planning and designing this tourist village is how to design a good tourist village architecturally, it is hoped that this tourist village will become the pride of its citizens and can develop tourism activities and increase the economic income of all its citizens.
\end{abstract}

Keywords: planning, design, village, tourism, architecture

\section{PENDAHULUAN}

Desa Ngepungsari terletak di bagian paling selatan di Kabupaten Karanganyar, berada tepat di persimpangan jalan antara tiga kecamatan yaitu Kecamatan Girimarto, Kecamatan Ngadirojo, dan Kecamatan Jatipuro, desa tersebut terdiri dari dusun: Jito, Kepuh, Nglasem, Ngledok, Pung Kulon, Pung Wetan, Sanan, dan Talang. Desa ini sebagian besar penduduknya bermata pencaharian petani dan sisanya sebagai pedagang, Pegawai Negeri Sipil (PNS), pegawai swasta, TNI, Polri dan lain- lain namun bila ditinjau dari prosentase mata pencahariannya penduduk desa tersebut lebih banyak yang merantau ke luar kota. Desa Ngepungsari memiliki hasil pertanian padi, jagung, kedelai, kacang tanah dan sisanya adalah komoditas sampingan sedangkan hasil perkebunan di desa ini adalah kelapa, dan kakao.

Sarana transportasi strategis di desa ini adalah bus dan minibus dengan jalur SoloWonogiri melalui Karanganyar. Wilayah desa tersebut memiliki posisi yang strategis karena berada di titik pertemuan jalur tiga kecamatan. Kondisi tersebut membawa efek pertambahan penduduk secara cepat sehingga meningkatkan mobilisasi manusia dan barang. Suatu wilayah yang pertumbuhan infrastruktur tidak terencana dapat menyebabkan tidak optimalnya proses kegiatan sosial dan ekonomi daerah tersebut.

Letak desa Ngepungsari yang strategis memiliki banyak lahan kosong yang tidak produktif namun memiliki potensi untuk dikembangkan menjadi lahan yang lebih produktif salah satu alternatif pengembangannya adalah kampung wisata, sehingga dengan adanya sarana tersebut diharapkan dapat meningkatkan pendapatan perekonomian masyarakatnya 
serta pengembangan sektor pariwisata desa tersebut khususnya dan di kecamatan Jatipuro pada umumnya.

\section{Gambar 1 Lokasi Desa Ngepungsari, Kecamatan Jatipuro, Kabupaten Karanganyar} (Sumber : Google Maps 2021)

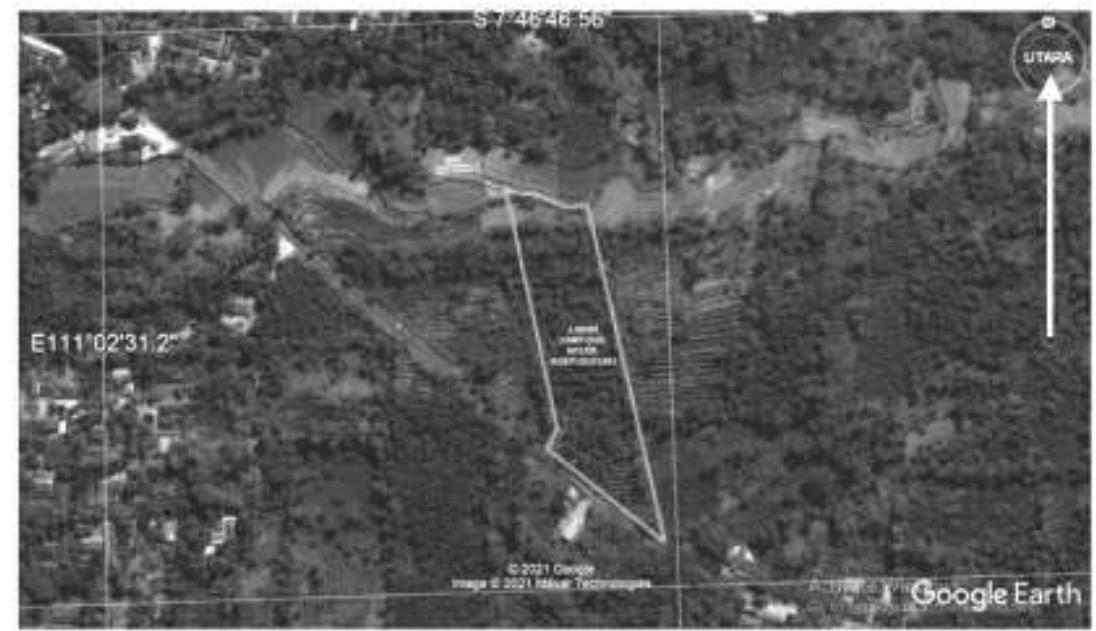

Gambar 2 Lokasi Lahan Kampung Wisata Ngepungsari

(Sumber : Google Maps, 2021)

Desa Ngepungsari memiliki Ruang Terbuka Hijau (RTH) yang berpotensi untuk diolah menjadi RTH yang fungsional untuk pengembangan sektor pariwisata dan peningkatan pendapatan ekonomi masyarakatnya. Pada kondisi sekarang ini RTH desa Ngepungsari tersebut berwujud lahan kosong, namun lahan tersebut kurang produktif disebabkan kendala secara umum pada manajemen pengelolaan dan potensi sumber daya manusianya. Team pengabdian masyarakat berusaha melakukan diskusi dengan perangkat terkait guna memperoleh data yang berhubungan dengan kondisi dan alternatif solusi pemecahan masalah tersebut. Ada beberapa point informasi yang diperoleh. Bahwa perangkat desa Ngepungsari menyadari potensi yang mereka miliki. Lahan kosong di desa Ngepungsari tersebut dapat digunakan untuk aktifitas peningkatan pendapatan ekonomi dan pariwisata yang sesuai dengan budaya sekitar.

Perangkat desa Ngepungsari juga memahami adanya perubahan kondisi internal dan eksternal kemasyarakatan yang harus dipikirkan demi kemaslahatan bersama. Perangkat desa Ngepungsari mempunyai harapan kedepan terkait pengelolaan lahan kosong tersebut. Ada kendala dari perangkat desa terkait solusi kedepan dan metoda yang harus dikerjakan guna perbaikan kondisi lahan kosong Ngepungsari. 
Berdasarkan permasalahan tersebut, maka dibutuhkan pendampingan oleh ahli bangunan dan ahli desain bangunan dan kawasan yang berpengalaman dan memiliki latar belakang pengetahuan di bidang Arsitektur.

Target luaran dari hasil pendampingan ini adalah:

a) Terwujudnya gambar denah dan kontur lahan kosong desa Ngepungsari.

b) Tersusunnya gambar site plan kampung wisata desa Ngepungsari.

c) Tersusunnya gambar detail rencana kampung wisata desa Ngepungsari.

d) Tersusunnya metoda pengurukan dan perbaikan tanah lahan kosong desa Ngepungsari.

\section{METODE}

Pelaksanaan pengabdian masyarakat di desa Ngepungsari dilaksanakan dengan tahapan:

\section{a) Tahap Persiapan}

Tahap persiapan dilakukan dengan cara diskusi dengan perangkat desa Ngepungsari tentang rencana pelaksanaan pengabdian masyarakat oleh tim Dosen. Dari diskusi tersebut diharapkan diperoleh informasi untuk menentukan langkah berikutnya demi terwujudnya kondisi yang diharapkan. Juga mulai direncanakan langkah aplikasi pengambilan data di lokasi lahan dan koordinasi dengan perangkat desa terkait otoritas wilayah berada di perangkat desa Ngepungsari. Otoritas tim pengabdian masyarakat Dosen hanya sebagai konsultan memberikan saran yang bersifat membangun dalam koridor rasional dan terukur dan tidak mempunyai kewenangan memutuskan.

\section{b) Tahap Pelaksanaan}

Kegiatan yang akan dilaksanakan pada tahap ini adalah:

1. Melakukan kompilasi data pengukuran dan foto, sebagai bahan proses analisis.

2. Melakukan analisis dan pemetaan tapak terhadap kondisi lahan kosong Ngepungsari.

3. Melakukan analisis ruang yang sesuai dengan kebutuhan.

4. Membuat gambar pra-desain berupa gambar site-plan, denah dan perspektif.

5. Dari bahan pra-desain yang telah disusun, dilakukan diskusi dengan semua tim dan calon pengguna untuk mendapatkan masukan dan saran untuk perbaikan pra-desain.

6. Setelah mendapat persetujuan gambar pra-desain maka dibuat perhitungan struktur gambar detailnya untuk gambar pelaksanaan konstruksi.

7. Penyusunan gambar detail untuk pelaksanaan konstruksi.

8. Penyusunan analisa yang diperlukan sebagai pendukung.

\section{HASIL DAN PEMBAHASAN}

\section{1. Survei Pendahuluan}

Survei pendahuluan merupakan kegiatan untuk mendapatkan informasi dan data awal yang diperlukan di lokasi pengabdian yang nantinya digunakan untuk analisis lebih lanjut. Pada survei pendahuluan ada beberapa tahapan yaitu :

\section{Tahap perijinan}

Sebelum melakukan survei pendahuluan, tim pengabdian akan memberikan surat tugas terlebih dahulu ke perangkat desa terkait.

\section{Survei lokasi}

Setelah menyerahkan surat tugas, maka tim merencanakan untuk melakukan survei lokasi. Berdasarkan hasil survei dapat diketahui bahwa akses jalan sudah baik karena mayoritas telah diaspal.

\section{Diskusi awal}

Diskusi awal dilakukan oleh Tim dengan salah satu perangkat desa saat berkunjung ke lahan tersebut, dari diskusi tersebut dapat diidentifikasi permasalahan yang ada, yaitu :

a). Banyaknya tanaman liar 
b). Kontur tanah yang tidak rata.

c). Belum tersedianya saluran drainase

d). Belum tersedianya sarana penunjang pariwisata.

Adapun gambaran permasalahan tersebut dapat dilihat seperti pada gambar berikut

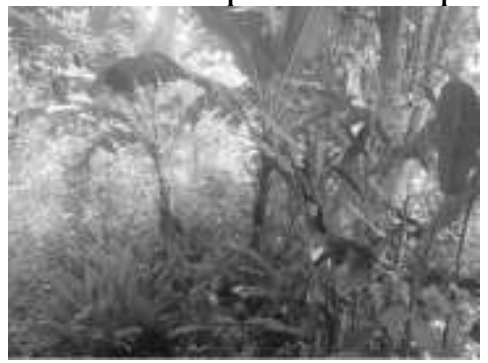

Gambar 3 Banyaknya Tanaman Liar pada Area yang Akan Direncanakan

(Sumber: Dokumentasi Tim PKM FT. UTP)

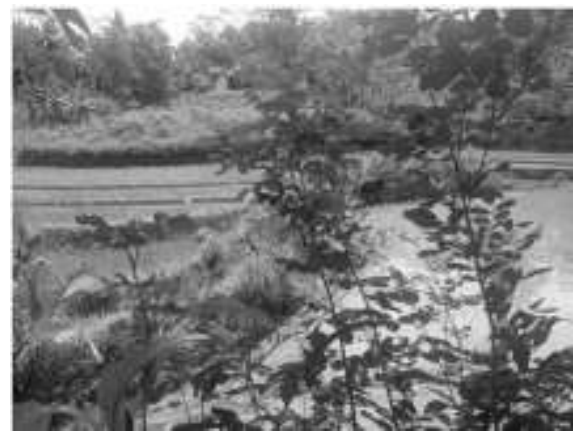

Gambar 4 Kontur Tanah yang Relatif Tidak Rata

(Sumber: Dokumentasi Tim PKM FT. UTP)

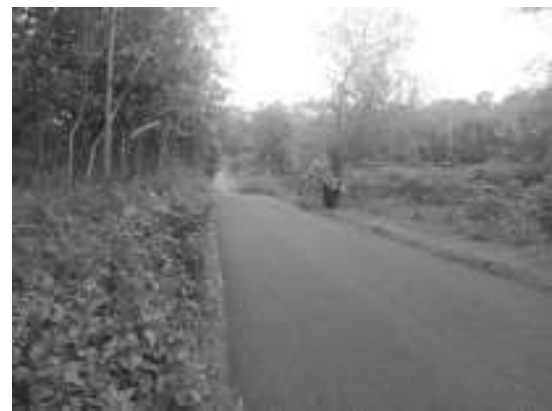

Gambar 5 Belum adanya Saluran Drainase Sekitar Lahan yang Akan Direncanakan (Sumber: Dokumentasi Tim PKM FT. UTP)

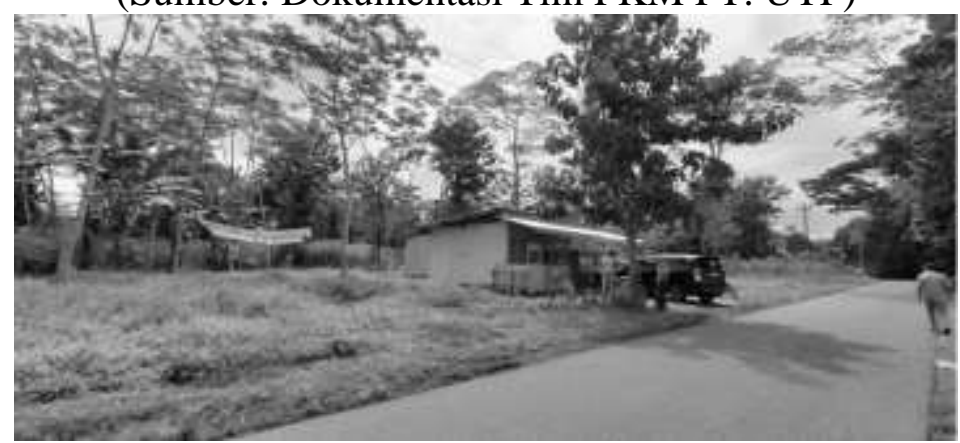

Gambar 6 Belum Adanya Sarana Penunjang Pariwisata yang Ideal

(Sumber: Dokumentasi Tim PKM FT. UTP)

\subsection{Pelaksanaan Pendampingan Perencanaan dan Perancangan}

Berdasarkan survei pendahuluan maka dilakukan beberapa kegiatan seperti berikut.

1. Melakukan kompilasi data pengukuran, dokumentasi foto, untuk di analisis.

2. Melakukan analisis kondisi tapak lokasi lahan kosong Ngepungsari. 
3. Melakukan pemetaan lahan kosong desa Ngepungsari.

4. Melakukan analisis ruang yang sesuai dengan kebutuhan.

5. Membuat gambar pra-desain berupa gambar site-plan, denah dan perspektif.

6. Dari bahan pra-desain yang telah disusun, dilakukan diskusi untuk mendapatkan masukan dan saran untuk perbaikan pra-desain.

7. Setelah mendapat persetujuan gambar pra-desain maka dibuat perhitungan struktur gambar detailnya untuk gambar pelaksanaan konstruksi.

8. Penyusunan gambar detail untuk pelaksanaan konstruksi.

\subsection{Penyusunan Analisa Perencanaan dan Perancangan}

Berdasarkan permasalahan yang ditemukan Tim Pengabdian, maka dapat disimpulkan pelaksanaan pekerjaan dibagi menjadi dua tahap pekerjaan, pada tahap I pekerjaan yang diprioritaskan yaitu:

a) Pekerjaan area parkir dan entrance serta area serba guna

b) Pekerjaan saluran drainase di tepi lahan kosong

c) Pekerjaan warung kuliner dan non kuliner (area UKM)

d) Pekerjaan kantor pengelola

Sedangkan untuk tahap II item pekerjaan diprioritaskan pada sarana pariwisata, meliputi:

1. Pekerjaan Masjid

2. Pekerjaan Gedung seba guna

3. Pekerjaan restoran dan gazebo

4. Pekerjaan kolam pancingan

5. Pekerjaan kolam renang dan sarana penunjangnya

Berdasarkan diskusi antara tim pengabdian dengan aparatur terkait maka disimpulkan bahwa prioritas pekerjaan saat ini diutamakan pada tahap I, untuk lebih jelasnya dapat dilihat seperti pada Gambar 7 sampai dengan Gambar 15

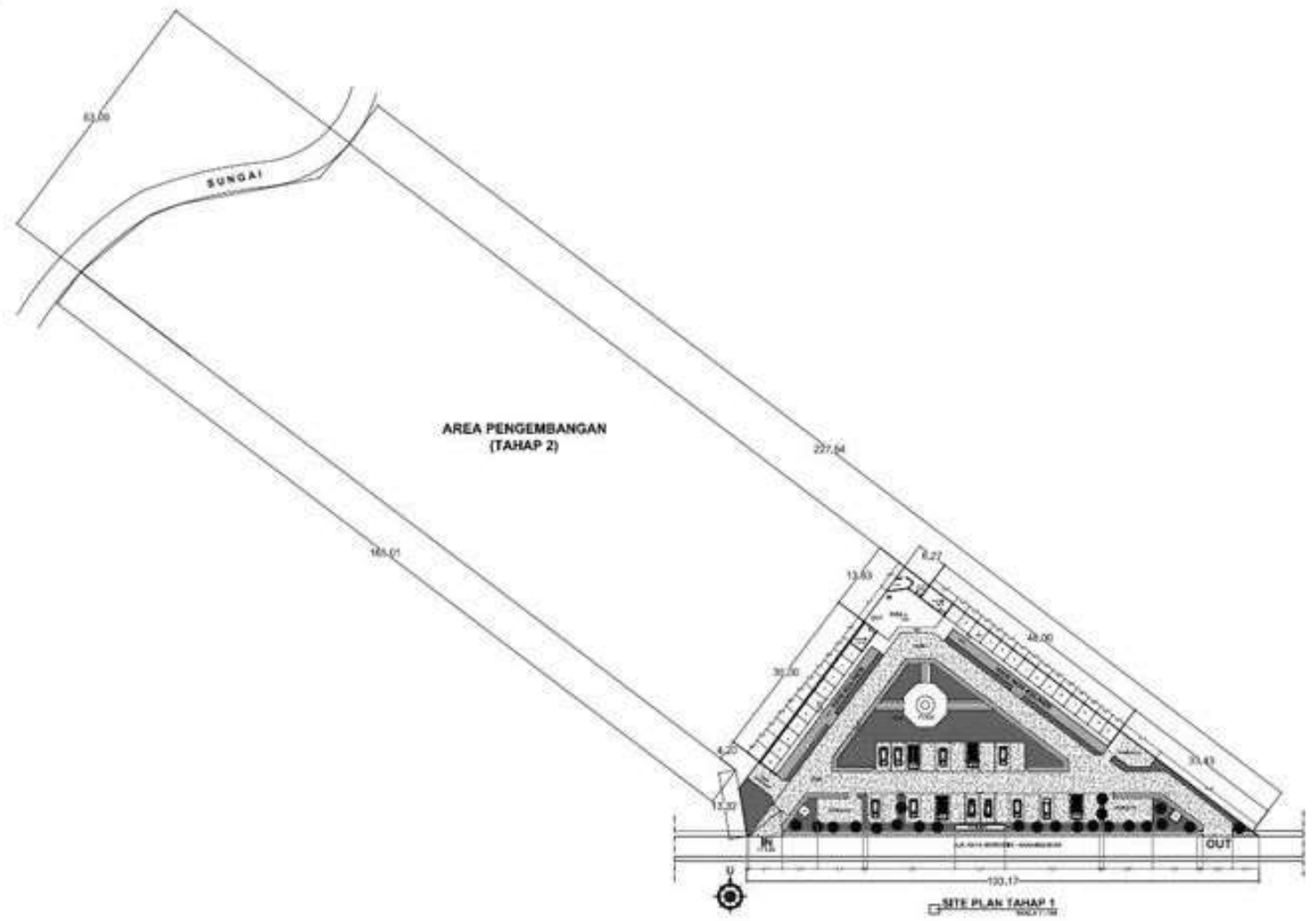

Gambar 7 Gambar Rencana Site Plan Tahap I Kampung Wisata Ngepungsari (Sumber: Tim Desain PKM FT. UTP) 


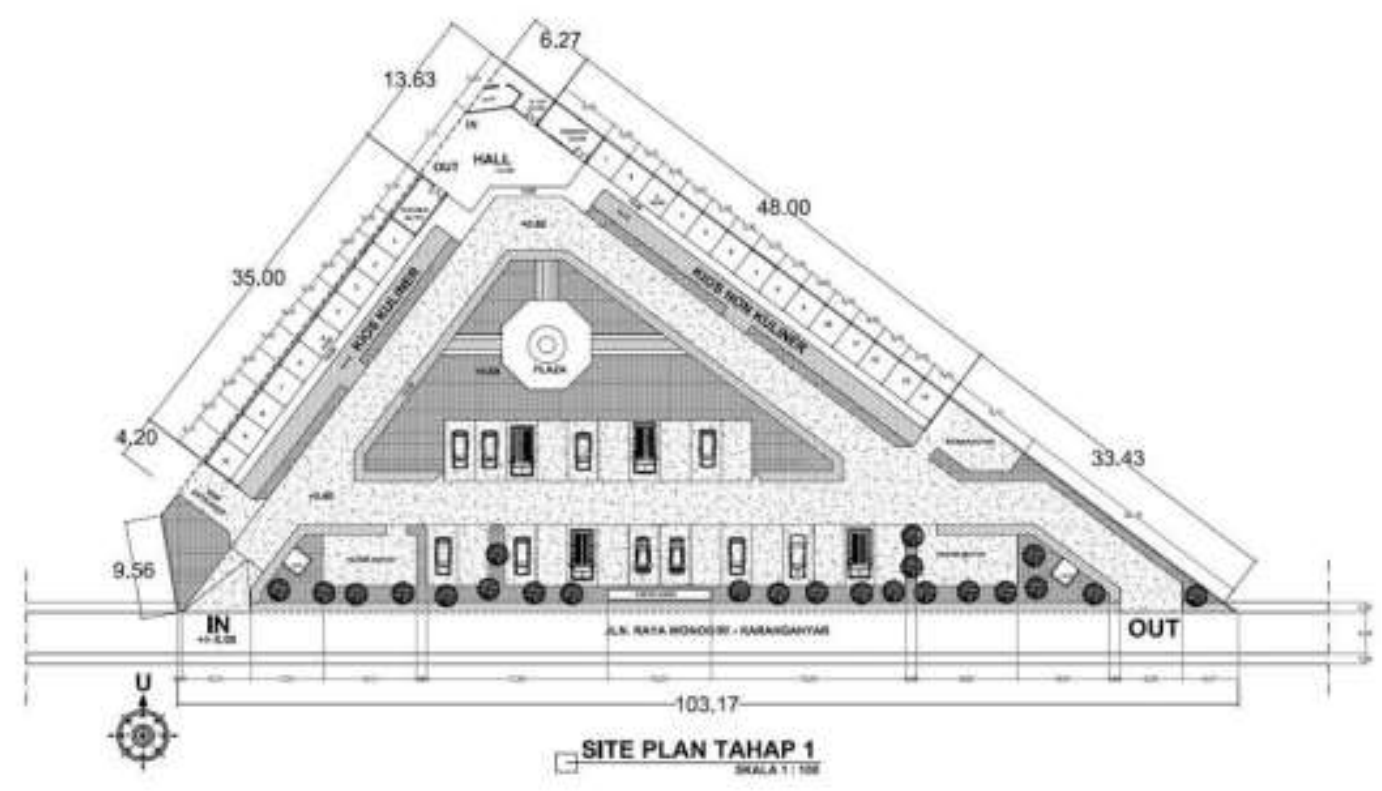

Gambar 8 Gambar Detail Site Plan Tahap I

(Sumber: Tim Desain PKM FT. UTP)

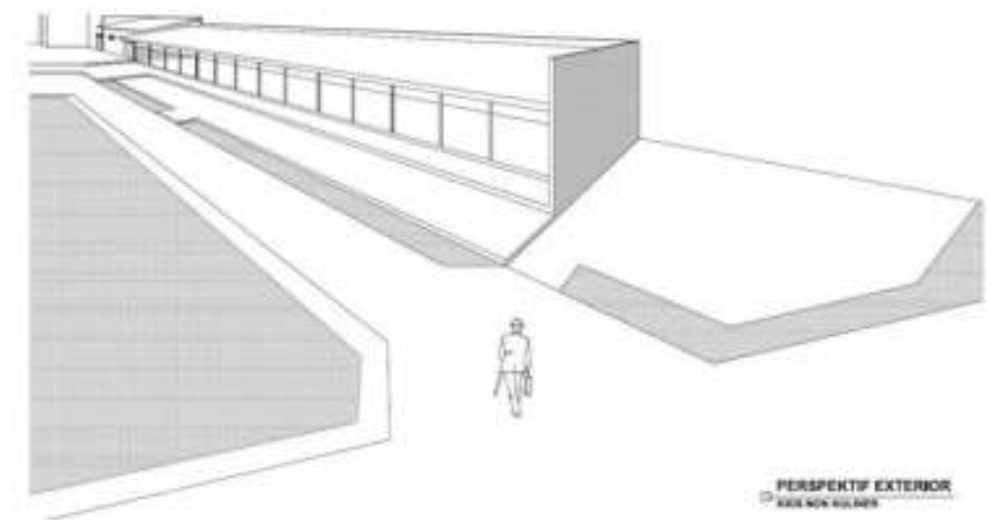

Gambar 9 Gambar Perspektif Exterior Kios Non Kuliner

(Sumber: Tim Desain PKM FT. UTP)

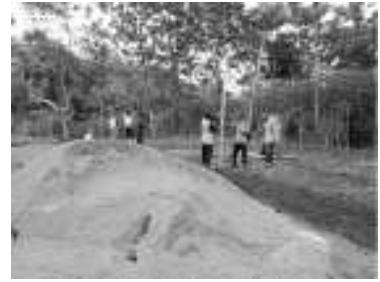

Gambar 10 Pembersihan Lokasi Lahan dari Tanaman Liar

(Sumber: Tim Desain PKM FT. UTP)
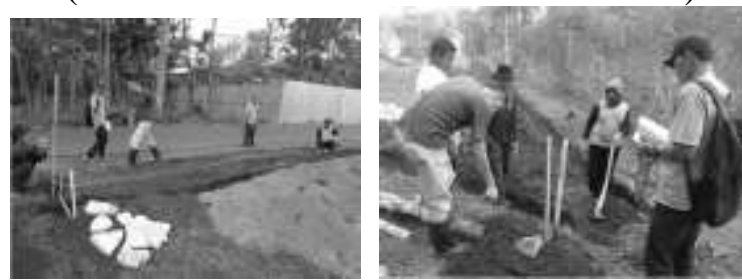

Gambar 11 Pengukuran Kontur Tanah dan Pemasangan Bowplank di Sisi Timur Lahan

(Sumber: Tim Desain PKM FT. UTP) 


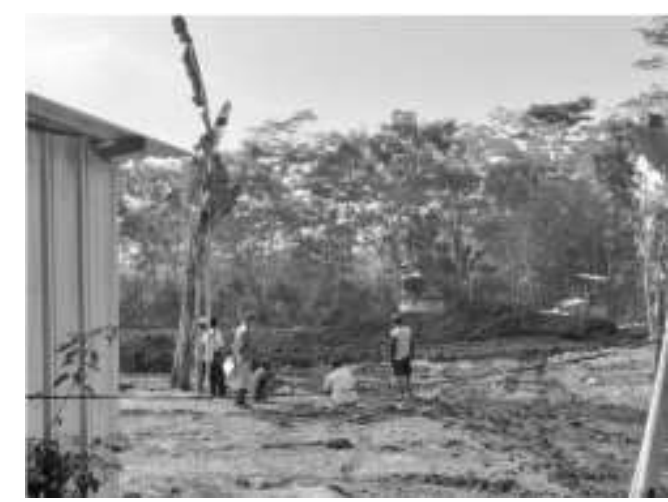

Gambar 12 Proses Pemangkasan dan Pengurukan Lahan (Cut and Fill System)

(Sumber: Tim Desain PKM FT. UTP)
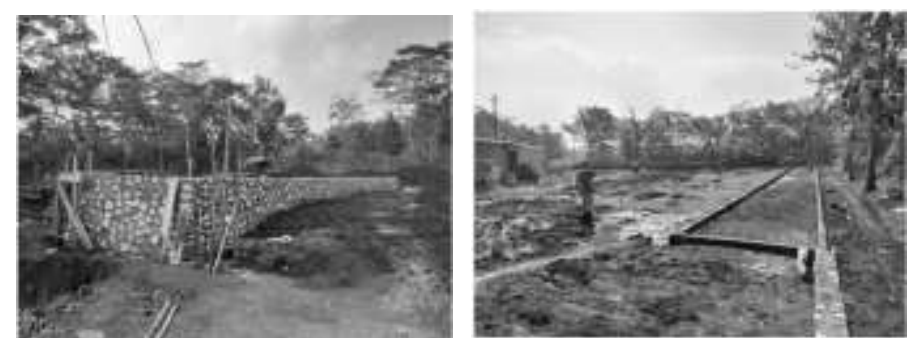

Gambar 13 Penambahan Talud di Bagian Barat Lahan dan Pembuatan Pondasi Batu Kali Warung Non Kuliner di Sisi Timur Lahan

(Sumber: Tim Desain PKM FT. UTP)

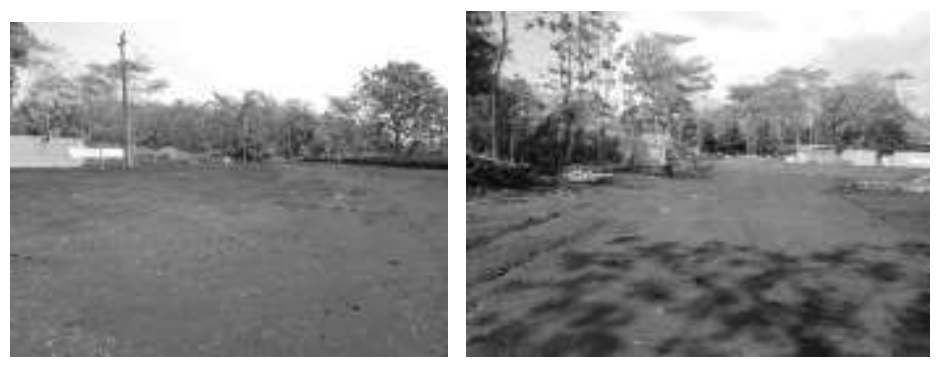

Gambar 14 Kondisi Kontur Tanah Bagian Selatan dan Utara Setelah Rata

(Sumber: Tim Desain PKM FT. UTP)

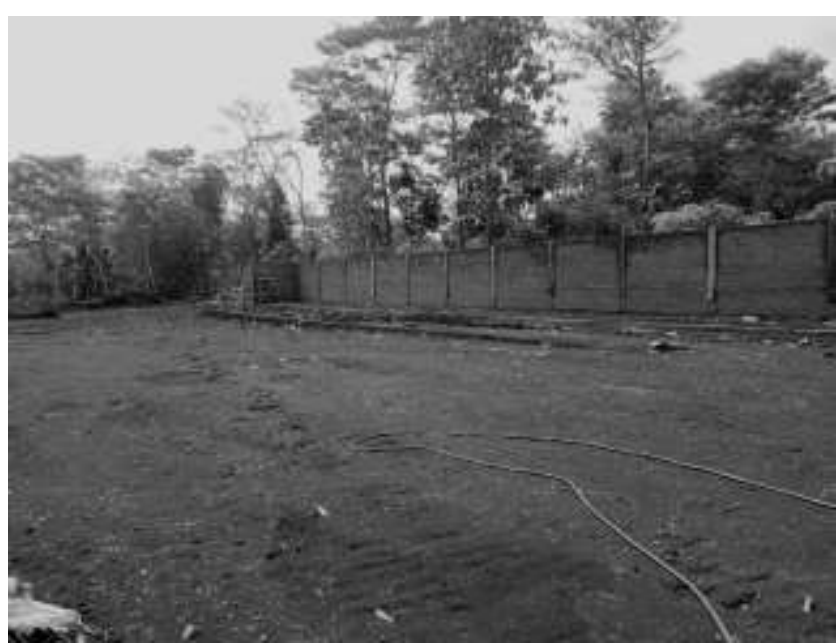

Gambar 15 Pasangan Batu Bata Dinding Kios Non Kuliner di Bagian Timur Lahan

(Sumber: Tim Desain PKM FT. UTP) 


\section{KESIMPULAN}

Tim Pengabdian Kepada Masyarakat telah melaksanakan pendampingan perencanaan desain tahap I Kampung Wisata Ngepungsari Jatipuro, dengan memberikan solusi pemecahan masalah yang ada, yaitu:

a) Kontur tanah yang tidak rata diatasi dengan sistem pemangkasan dan pengurukan

b) Merencanakan dan merancang fasilitas wisata dan kebutuhan ruang pada lahan tersebut agar produktif dan berfungsi optimal.

c) Mengalokasikan sarana peningkatan pendapatan ekonomi masyarakat desa Ngepungsari di lahan tersebut dalam wujud warung kuliner dan warung non kuliner.

Kegiatan pendampingan akan lebih sempurna apabila dalam pelaksanaannya berpedoman pada gambar desain yang sudah fix dengan pengawasan yang optimal agar hasil pelaksanaan pembangunan sesuai dengan perencanaan.

\section{UCAPAN TERIMA KASIH}

Penulis mengucapkan terima kasih kepada aparatur desa Ngepungsari, Kecamatan Jatipuro, Kabupaten Karanganyar yang telah memberikan kesempatan untuk melaksanakan kegiatan di lokasi terkait.

\section{DAFTAR PUSTAKA}

Ernawati, dkk. (2006). Pengaruh Sosial Budaya Ekowisata Berbasis MasyarakatTerhadap Masyarakat lokal di Taman Nasional Gunung Halimun, [Penelitian], Universitas Sebelas Maret, Solo.

Defining Cultural Tourism. International Converence on Civil, Architecture and Sustainable Development, 70-74.

Hakim, Rustam 2003. Komponen Perancangan Arsitektur Lansekap, Prinsip-Unsur-dan Aplikasi Disain".Jakarta: BUMI AKSARA

Jafari, J., \& Ritchie, J. R. B. (1981). Toward a Framework for Tourism Education: Problems and Prospects. Annals of Tourism Research,8 (1), 13-34

Maharani, I. (2010). Tinjauan Umum Kampung Wisata. Kampung Wisata, 31-44. Sharpley, R. (2000). Tourism and Sustainable Development: Exploring the Theorectical Divice. Journal of Sustainable Tourism

Wijayanti, A. (2017a). Analisis Dampak Pengembangan Desa Wisata Kembang Arum Terhadap Perekonomian Masyarakat Lokal. Tesis. Sarjana Wiyata Tamansiswa Yogyakarta 